\title{
Designing an Experiential Exhibition for Raising Public Awareness of Cultural Sounds to Safeguard Sonic Intangible Cultural Heritage Values
}

\author{
Pınar Yelmi and Sertaç Kakı
}

\begin{abstract}
This paper outlines an experiential exhibition that intends to increase public awareness of cultural sounds of Istanbul. Since intangible cultural heritage (ICH) elements can only be safeguarded within society, it is necessary that the society is aware of cultural values and conscious about protecting them. In order to raise public awareness of sonic cultural values, we designed an exhibition to emphasize the cultural significance of urban sounds through sonic experiences. The exhibition is shaped by experience design, as experience is one of the most powerful ways of conveying a message. Moreover, the exhibition consists of only sounds and texts, but no visuals in order to draw attention on urban sounds and to keep visitors focused on thinking about these cultural values. This experiential exhibition leads to a raise in public awareness of urban sounds, which hopefully triggers protecting cultural values voluntarily and help turning the action of collecting and archiving urban sounds into a collaborative work.
\end{abstract}

Index Terms-Experience design, experiential exhibition, auditory experience, intangible cultural heritage, sonic values.

\section{I.INTRODUCTION}

Urban fabric includes traditions, daily life routines, and cultural activities of a society. Sounds that are related to traditions and culture are considered intangible cultural heritage (ICH) elements, and therefore they deserve to be protected for cultural sustainability [1]. However, there are debates about ways of protecting intangible cultural heritage elements, whether it can be protected in museums or whether it is possible to safeguard them in society.

Ruhi Ersoy discusses the types of cultural heritage that can and cannot be exhibited in museums, in order to understand if exhibiting culture in glass cases can really protect it or just display a frozen version of it. According to Ersoy, exhibiting ICH in a museum means pulling ICH out of its context. Instead of putting ICH in a museum, transforming ICH's place of origin into a museum would be a more appropriate approach in the sense that visitors can experience it in its own context [2]. Baghli also advocates the idea of rethinking the definition of museums when it comes to the safeguarding of ICH [3]. Ekici, however, summarizes the outcome of the Symposium on Exhibiting the Intangible Cultural Heritage in a Museum in 2004 as follows: there is a

Manuscript received February 24, 2019; revised May 2, 2019. The Soundscape of Istanbul project was realized by the financial support of Koç University. The experiential exhibition (Duyduk Duymadık DeNeyiM!) was realized by the financial the support of Studio-X Istanbul and Koç University.

Pınar Yelmi is with Işık University, Istanbul, Turkey (e-mail: pinar.yelmi@isikun.edu.tr).

Sertaç Kakı is with ITU, Istanbul, Turkey (e-mail: kaki@itu.edu.tr). consensus on the safeguarding of ICH, and one of the most effective ways of doing so is its musealization, by using recent technology and improving education in museums [4]. $\mathrm{He}$ also adds that musealization would not be enough unless ICH elements are sustained within society or unless the museum has visitors. Tongyun Yin has analyzed the challenges for museums to safeguard ICH in his research sponsored by the Smithsonian Institution and has found several contradictions between the nature of museums and ICH: museums are static, but ICH is dynamic; museums deal with materials from the past, but ICH is about the past, present and even the future; museums are categorized according to their collections (history, anthropology, fine art), but ICH consists of social, natural, cultural, and spiritual values; and lastly museums are places of judgments and decision at each step (such as what to include in a collection, what to exclude, how to interpret or present it), but ICH is completely neutral and directly reflects life itself [5]. Museums across the world, including the ones that were established in the early Republican Period in Turkey [6], have missions towards the adoption of cultural values by societies. They have always been closely related to the nation, culture and society, just as what Southern has declared: 'Museums are central to our culture, to our sense of ourselves, and to the future of our country' [7]. The collections that museums display are crucial for their institutional stand. For this reason, collection pieces need to be chosen by applying significance assessment tests which are mainly used to evaluate the importance and relevance of the objects to the entire collection and to the institution itself [8]. Therefore, museums play a great role in preserving national values and making public conscious of their uniqueness. When considered ICH, however, museums may not be the most suitable places for directly protecting dynamic heritage elements, as it is also argued by Ersoy, Baghli and Yin. ICH elements need to be maintained and safeguarded in their own contexts within the society to which they belong. Moreover, ICH elements need a dynamic and sustainable safeguarding since it evolves over time. In this paper, we discuss our exploration for raising awareness of ICH elements by indirect means of exhibitions, and for encouraging public to safeguard their own cultural values through exhibitions.

\section{INCREASING PUblic AwARENESS OF CULTURAL SOUNDS BY MEANS OF AN EXPERIENTIAL EXHIBITION}

Sounds do not receive much attention, despite being very important in everyday life. They are mostly ignored in contemporary Istanbul, as in other visual dominant cultures. However, this may have been different in another time period; with the invention of print, the importance of auditory 
and olfactory communication decreased or in different cultures; societies may have different ways of understanding the external world. For example, most indigenous cultures of Latin America are based on the thermal dynamics of lands and bodies, the Ongee of the Andaman Islands communicate and cure with smells and control their cosmos with odors, and for the Suya of the Brazilian Mato Grosso, hearing is a symbol of social individuals. The reflection of the significance of hearing can be observed also in their language, as they use the verb 'to hear' in order to mean 'to understand'. In western cultures, however, visual elements are more dominant and visual terms are more common, such as 'I see', 'point of view', 'enlighten', and so on [9]. Contemporary Turkish culture is also mainly based on visuality, although its roots are to be found in the Ottoman Empire's culture, where sound, such as Qur'an recitals and the call to prayers [10], were vital elements of daily life. Such sounds play significant roles not only in terms of religion, but also for temporally organizing everyday life. For example, shopkeepers use to open and close their shops according to the call to prayers as they are heard five times at certain intervals.

Despite the fact that sounds are mostly ignored in daily lives of visually dominant cultures, they are significant values in the context of intangible cultural heritage, and they need to be protected just like any other cultural value. For this reason, with the aim of protecting sonic values and raising public awareness of their cultural importance, we initiated The Soundscape of Istanbul project (soundscapeofistanbul.ku.edu.tr) in which we determined, collected and archived the representative urban sounds of Istanbul [1]. In the project, following a survey for determining symbolic sounds of Istanbul by public participation, we conducted field recordings during one year for collecting symbolic sonic values. Then, we archived these sound recordings in a publicly accessible archive, Koç University Suna Kiraç Library Digital Collections (http://digitalcollections.library.ku.edu.tr/cdm/landingpage/c ollection/SOI). This sound collection is also shared with Europeana Sounds portal, which is a European organization that aims to protect the sound heritage of Europe.

The sound heritage of Istanbul, however, is not limited to sounds that we recorded and archived. It may be enriched with the sounds recorded in different time periods and in different locations within the city. In order to turn this static sound collection into a dynamic and sustainable archive, we developed an interactive web-based platform, The Soundsslike Project (soundsslike.com), which enables volunteers to upload sounds to the archive [11]. Thus, the Soundsslike archive intends to collect sonic values by crowdsourcing method, which leads to a collaborative action towards safeguarding the sound heritage of the city within society.

In order for the society to contribute with their own sound recordings to the Soundsslike archive, the project needed to be introduced and public awareness needed to be increased. For this, we designed an interactive exhibition in which visitors could directly be involved in the exhibition. Visitors had the opportunity to shape the sonic environment of the exhibition area by playing various sounds of their choice. Moreover, visitors had the chance to upload their own sound recordings to the Soundsslike archive that could be listened to in the exhibition area simultaneously. We conducted both quantitative and qualitative research about the contributions of the exhibition towards raising public awareness of urban sounds and safeguarding sound heritage, which are explained in more detail in another article [11]. To explain briefly, according to the survey conducted in parallel to the exhibition, it can be inferred that public awareness increased as we received many sounds recordings uploaded to the Soundsslike archive. According to our observations during the exhibition, visitors seemed to be highly engaged with the exhibition and spent around $20 \mathrm{~min}$. discovering urban sounds of Istanbul. It was very promising to see visitors connected to their cultural values and to witness that they care about urban sounds and make efforts to safeguard the sound heritage of their own hometown.

After this successful interactive exhibition, we continued our exploration for different ways of designing exhibitions in order to raise awareness of urban sounds and to safeguard sound heritage. We conducted research on experience design and designing an experiential exhibition for the same objectives, since experience is one of the most powerful communication tools. Any moment of our lives can be taken as an example of experience; they are important for shaping our successive behaviors, feelings or thoughts. Henry James summarizes this idea: 'The quality and content of a person's life is the sum total of what they've paid attention to over time' [12]. Experiences may come in a great variety, from analog to digital, cultural to technological, and individual to interactive. All these experiences interpenetrate into each other in real life. There are mainly six key dimensions that characterize experiences: significance, breadth, intensity, duration, triggers and interaction [12]. In a potential experiential exhibition, all the principles of experience should be considered, particularly sensorial triggers (taste, sight, sound, smell, touch) and cognitive elements (concepts and symbols) [12]. Hearing is one of the most important sensual perceptions, and auditory elements not only convey information, but also stimulate emotions and bring back memories. Therefore, the intention of the exhibition is to communicate with the public through sonic experiences and make them realize the uniqueness of cultural sounds.

In this paper, we explain the design process of the experiential exhibition (Duyduk Duymadik DeNeyiM!), the results of the survey conducted to evaluate the exhibition in terms of its contributions to safeguarding the sound heritage, and we discuss if sound heritage can be safeguarded by means of an experiential exhibition.

\section{EXHIBITION DESIGN}

In this experiential exhibition (Duyduk Duymadık DeNeyiM!), which is the second exhibition after the interactive one, we had the intention of highlighting the significance of sonic urban values and safeguarding of sound heritage by raising awareness of cultural sounds. We focused on two points when designing the exhibition which helped realizing our intention: forging links between the (static) exhibition space and the (dynamic) urban space of Istanbul through sonic memories awaken by the cultural sounds heard in the installation as well as the parallel events (for example, by means of soundwalks), and making visitors aware of the 
uniqueness of their sonic culture, which may, then, lead them to safeguard this very culture and heritage within their daily life voluntarily.

Regarding the exhibition content, we focused on disappearing urban sounds and on the most ignored cultural values in daily life. This idea was both inspired by the quotation 'Where are the museums for disappearing sounds?' [13] of a pioneer researcher in the field of soundscape studies, R. Murray Schafer, and by the results of the survey that we conducted at the beginning of The Soundscape of Istanbul project. This online survey, which was actually done for determining the characteristic urban sounds of Istanbul, put forward also the fact that the most ignored sounds in daily life are historically rich and culturally significant ones. Yelmi discusses the survey and its results widely in another paper [14]. These ignored cultural sounds include street vendors (Turkish bagel vendors, vendors of roasted chestnuts, boza sellers), tea, narghile, kokoreç, backgammon, the nostalgic tramway, markets and bazaars, and horse-drawn carriages [14]. Therefore, it became inevitable to emphasize the cultural significance of especially these ignored sounds in the exhibition.

We aimed to draw attention not only on these ignored sonic values but also on sound itself as a displayed object rather than background or side elements in the exhibition area. With this aim, we explored the most effective ways of emphasizing disappearing urban sounds by highlighting their historical richness and cultural significance, conducting a research about how auditory perception is affected by visuals and how sonic dominance can be set.

People tend to recognize and identify their surroundings by seeing rather than listening, as Posner's theory explains the visual dominance over other senses [15]. Another reason may be that visuals carry more accurate information and prevent the unpredictability and uncertainty, thus make people safe when perceiving. Jian Kang's quote 'compared to vision, sound perception is usually information-poor but emotion-rich' [16] also verifies this situation.

Audio-visual studies generally cover enriched experiences, which come out as a result of combination of sound and image or the studies on how audio affects visual perception when they are used together. This literature goes mainly over films, sound design and sound editing. When sound and image are used together, they create an augmented experience in terms of sensory perception levels. Since sound evokes emotions, it directly changes the value of a simple scene or a picture. This can be described as added value which Chion explains as '... the expressive and informative value with which a sound enriches a given image so as to create the definite impression, in the immediate or remembered experience one has of it, that this information or expression 'naturally' comes from what is seen, and is already contained in the image itself' [17]. Gary Rydstrom, who has won best sound and best sound editing academy awards with the films Saving Private Ryan, Titanic, Jurassic Park, and Terminator 2, supports this idea by stating '..there is a magical level reached when picture and sound work together. When approached creatively, the combination of sound and image can bring something to vivid life, clarify the intent of work, and make the whole experience more memorable' [18].
Besides contributing to the value of visuals, sound changes their perception as well. Especially music makes people think with their emotions. Muzaffer Çorlu, an awardwinning classical guitarist, has conducted a research on how music affects the visual perception and gave a talk called 'Do we 'see' with our ears too?' [19] which is mainly about his research results. In his research, he showed to first group of people a scene with the red dressed girl from Schindler's List without music and asked about their opinion. They all gave responses on the quality of the film and scenario. Then, he showed the same scene with the soundtrack of the film to second group of people and asked the same question. They all commented on that scene declaring pity about the savagery. As we can obviously infer from this example, people leave rational thinking and respond with their emotions with the presence of music. This is a very strong evidence that audio carries great importance in presenting and perceiving visuals. Our question, however, is about exploring the reverse relation between audio and visual, thus we intended to understand how visuals affect auditory perception, and to observe effects of audios and visuals separately and together on perception and on experience.

For this reason, we conducted a study to understand how people perceive the context when they only listen to a sound, when they listen to a sound and then view a related photo, when they view a photo and then listen to a related sound, and when they view a photo while listening to a sound at the same time. We prepared a set of four items including a sound file, a file containing sound in the first place followed by a visual, a file containing visual in the first place followed by a sound and a file containing both visual and sound at the same time. Together with these items, we asked questions about what these sounds could be, if the visuals and sounds were compatible with each other or if they belonged to anything else. Besides their answers, we also observed the way in which they responded; for example, if they searched clues only in the visuals or if they directed their attention to the sounds. In this study, we involved random participants of different backgrounds, education levels and nationality, as there might have been a difference in perception due to familiarity or unfamiliarity with culture. For this, we also searched answers in the interviews with the locals of Istanbul, if several cultural sounds (for example, narghile or kokoreç) become a habit or already lost in daily life and they do not even hear them anymore or if they are aware of the importance of urban sounds and approach them consciously. In the interviews with the non-locals, we explored if it is easy to understand the origins of sounds.

To summarize the results of this study, none of the participants could guess the right answer when they only listened to the sound, and almost all of them needed to see a visual to be sure about the origin of sound. When only sound was given, everyone linked the sound with something in their lives depending on their imagination, worldview, knowledge, origin, and own traditions; thus all the answers were different from each other. When they were given the photo and the sound file separately, they mostly tended to build their answers based on the visual. Even if they had a different answer before seeing the photo, they changed it according to the visual. When visual was given first and then followed by sound, participants tended to perceive the sound as if it be 


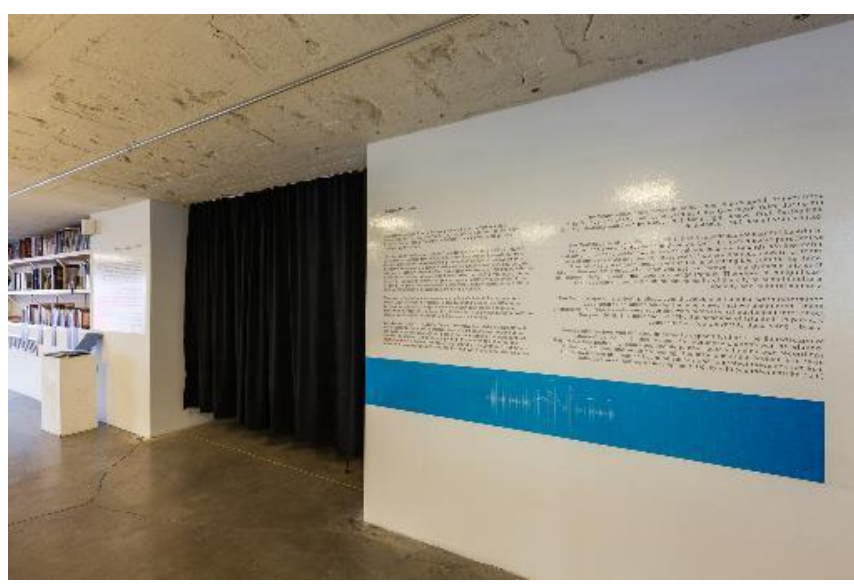

Fig. 1. Exhibition. (Photo credit: Sahir Uğur Eren)

longed to the visual. Even if they did not think that they were compatible, they could not think independently from the visual and they made their guesses highly related to the visual. They also added that if they have not seen the photo first, they could most probably have thought something else. When sound was given first and then followed by visual, participants tended to refuse that the visual did not belong to sound because they already had an idea about the sound before seeing the visual. However, they still could not be so sure and responded with a possibility. When they were given the photo and the sound file at the same time, almost all of them were focused on the photo. If they could not find any clues in the photo, some directed their attention to the sound as a second step, and some of them did not even think about listening and declared no answer. There were only few participants who listened to the sound in the first place. Most of those who have focused directly on the sounds had musical background, and even them asked for more informative sounds or visuals to be sure about the context.

Therefore, according to survey results and our observations, people generally tend to perceive things by seeing rather than by listening since visuals are more dominant in making people believe just like the phrase 'seeing is believing' and visuals carry more information than sounds. Sound itself, solely, evokes emotions and imagination, and does not always carry accurate information. According to Kang, 'there are two types of sounds related to the different ways of processing in terms of the users' listening; holistic hearing and descriptive listening. The former takes soundscape as a whole without making any meaning and the latter focuses on identifying the psychological and social dimensions of a sound source' [16]. When people try to recognize origins of sounds, several factors such as psychological, linguistic and social, interfere with this process, and everyone comes up with a different conclusion. For this reason, it is very difficult to link a sound with a certain event or location because sounds are connected with so many different things in everyone's memory. We have foreseen that familiarity with culture could create differences in perception of urban sounds in the beginning of this study. However, this research has also appealed that cultural familiarity plays only a small role in recognizing a sound without its context. It highly depends on individual's background, interests and so on. Thus, an exhibition designed only with sounds will be experienced differently by everyone since there will not be

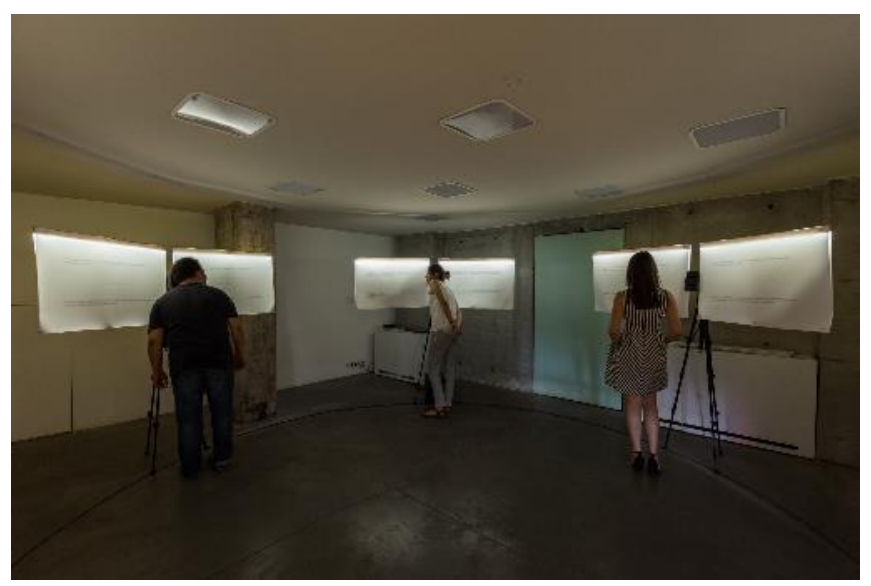

Fig. 2. Exhibition. (Photo credit: Sahir Uğur Eren)

only one single meaning to infer. However, if there is a certain message to convey through the exhibition, it will be more efficient to use supportive elements besides sounds.

In order to convey the message of our exhibition, we chose to use texts besides sounds since visuals dominate the attention and leave sounds in the background. Absence of visuals in the exhibition would be powerful in emphasizing the significance of cultural sounds through sonic experiences and keep the attention on sounds. We intended to convey one single obvious message by creating unique experiences for each visitor with using only sounds and texts.

In the exhibition, sounds of ten ignored cultural values (Turkish bagel vendors, vendors of roasted chestnuts, boza sellers, tea, narghile, kokoreç, backgammon, the nostalgic tramway, bazaars, and horse-drawn carriages) were accompanied by texts. The texts that we prepared for exhibition did not have a detailed explanation about the sounds and did not say exactly what they were, on purpose. Texts only gave little information highlighting the cultural importance and historical richness of those sonic values with one sentence. Our intention, here, was to make visitors actually listen and think about the sonic values of everyday life, by providing a small textual clue but no visuals.

The idea for the sound installation was using a 5.1 surround system, which enabled using a 360-degree sound environment, a realistic feel and blend of recorded sounds. We located five speakers as a circle shape, which defined the borders of the installation and the navigation area for visitors (Fig.2). The preparation of the sound installation was mixing ten recorded audio files in five main surround channels by using two sounds in each channel. Thus, every single surround channel fed by two chosen sounds except the sub-bass channel. By this way, we intended to give a conceptual feeling in every different channel by choosing significant cultural sounds for listeners. We created concepts on each channel which were; 'Beyoğlu street' using nostalgic tramway and kokoreç sellers' sounds, 'Nostalgia' using boza sellers and horse-drawn carriages' sounds, 'Bazaar' using bazaar and vendors of roasted chestnut sounds, 'Turkish coffee house' using narghile and backgammon sounds and 'Traditional ferry breakfast' using tea and Turkish bagel vendors' sounds. These concepts also helped shaping the bilingual texts (Turkish and English), which were printed on ten boards, one for each sound. We located text boards, as they would be on both left and right sides of all five speak- 
ers. This helped listeners to make a correlation more easily between texts and sounds. When listeners approached to read the texts they could also hear the relevant sound more obvious than others, and they could connect this specific sonic value with its textual clue.

The installation was mainly in dark and only the texts were lighted in order to put emphasize on sonic values. The whole idea behind this installation was to make visitors experience the chaotic sonic environment of Istanbul and to make them realize that each single urban sound is, in fact, of great significance in terms of cultural heritage. When visitors stood in the center of the circular shaped installation, they could hear all ten sounds at the same time as chaos, and it was difficult to distinguish sounds from each other. However, when they approached to any speaker, which had two text boards by its sides related to two sounds of its concept, it became clear to distinguish especially these two sounds with the help of textual clues. Thus, the visitor left the chaotic sonic environment behind by moving from center towards the borders of the installation and focused only on these two sounds trying to bridge sonic values with the textual clues. Encouraging visitors to think on cultural sounds not only strengthened the bond between the visitor and the installation but also revived visitors' sonic memories related to the city.

Furthermore, we took the advantage of the centrally located exhibition gallery (Studio-X Istanbul) and we organized soundwalks, walks focused on listening, during the exhibition in order to enhance sonic experiences. Therefore, visitors could connect the exhibition space with everyday life of the city and had more time to internalize the significance of urban sounds.

\section{IV.EXHIBITION EVALUATION}

We wanted to learn more from visitors if we could reach our aims through this experiential exhibition. For this reason, we conducted a visitor research preparing a short questionnaire that measured (1) if the exhibition played role in increasing public awareness of cultural sounds, (2) if using only sounds and texts enhanced experience, and (3) if the visitors could bridge their daily lives and memories with the sounds used in the exhibition.

For visitor research, we prepared a very short computerbased questionnaire with seven questions and a likert scale not to overwhelm the visitors. We located the computer on the way out of the exhibition (Fig.1) so that visitors could fill in after visiting the exhibition. Survey statements can be classified in three categories according to the objectives of the exhibition; (1) 'increasing awareness', (2) 'effects of an entire sonic experience' and (3) 'the relationship between visitors and the sounds'. The statements were as follows; for the first category, 'I didn't realize the cultural value and importance of these sounds before, although I hear them almost everyday.' and 'My awareness of these sounds increased thanks to this exhibition.'; for the second category, 'If visuals were used, I could have imagined the sounds more easily.', 'Sounds and texts are adequate to understand

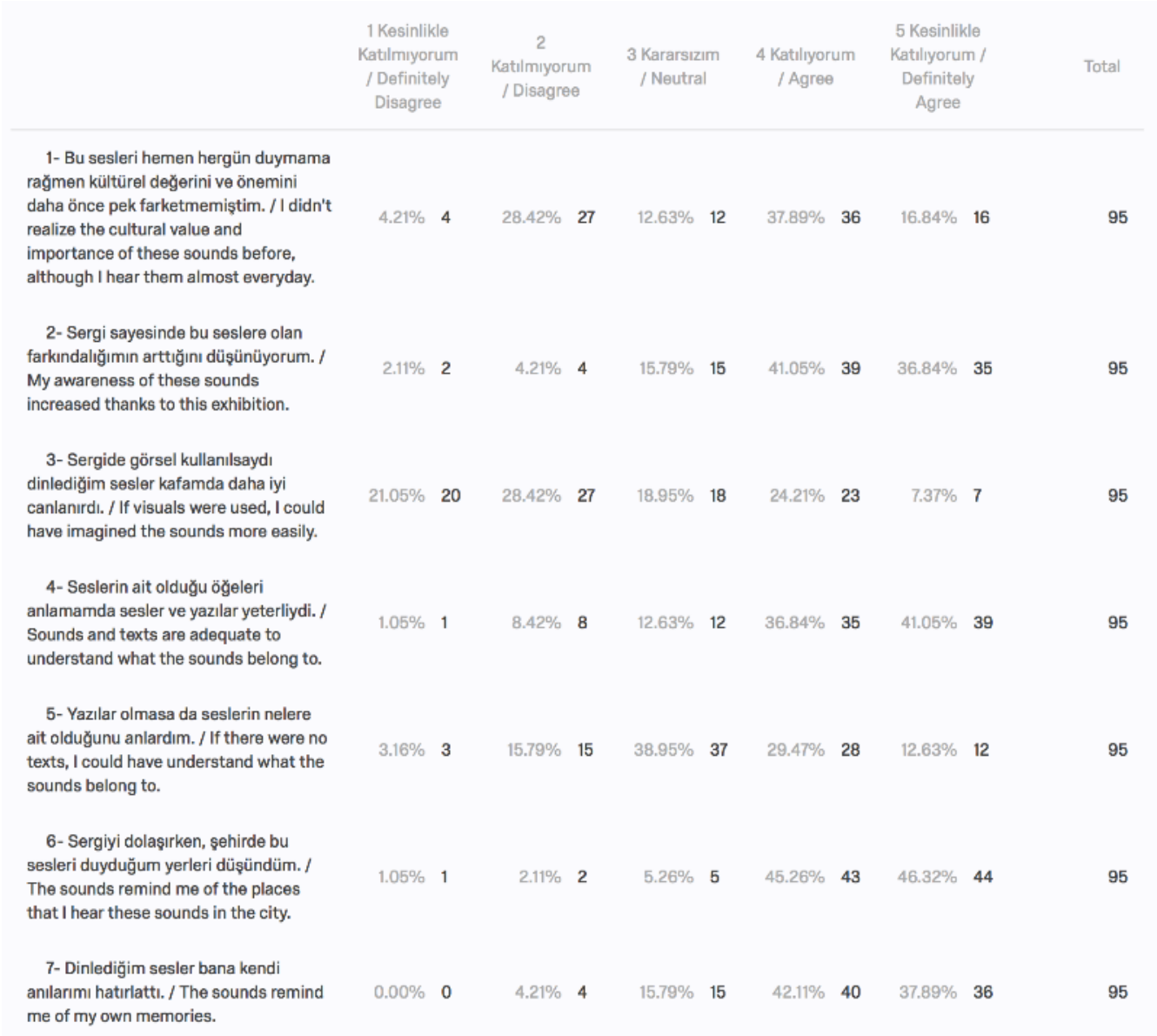

Fig. 3. Survey results. 
what the sounds belong to.' and 'If there were no texts, I could have understand what the sounds belong to.'; and for the third category, 'The sounds remind me of the places that I hear these sounds in the city.' and 'The sounds remind me of my own memories.'

In total, 95 visitors completed the survey and the results are shown in the table above (Fig.3). Concerning the two statements in the first category (1), it can be inferred that the exhibition played a significant role in raising public awareness of cultural sounds. Around 55\% of the participants declared that they did not realize the cultural value and the importance of sounds until they visited the exhibition, and around $78 \%$ of the participants stated that their awareness of the urban sounds increased thanks to this exhibition. In addition to visitors' answers in the survey, there was an obvious increase in the uploaded sounds to the Soundsslike archive. Therefore, it can be said that the exhibition was effective in terms of raising awareness of urban sounds.

Regarding the questions querying the design choices in the second category (2), the overall outcome fits what we expected according to our previous study about the effects of audios and visuals on perception. Around $50 \%$ of the participants would have difficulty in understanding the sounds without visuals and the rest could have guessed without visuals. According to (around) $78 \%$ of the participants, sound and texts were adequate to guess what the sounds actually belong to, although they had some difficulty. Around $48 \%$ of the participants stated that they could not guess the sounds without textual clues. Thus, we can verify one more time that sounds carry less information and people pay less attention to sounds so that recognizing sounds without clues becomes difficult even if they are heard often in daily urban lives. However, providing textual clues in the exhibition made guessing the sounds easier. It also helped reviving personal memories for each visitor; thus, the experience became unique as well. Besides these, visitors could take the message from the exhibition and they could connect with urban sounds through a strong emotional bond. If there were visuals related to sounds, it was more likely that visitors would have an objective attitude to urban sounds. Therefore, designing a sound exhibition by using only sounds and texts is a successful combination in terms of reflecting personal experiences within daily urban life, and in making visitors embrace cultural sounds and comprehend the significance of urban sonic values.

The results of the last two questions in the third category (3), however, prove that there is a strong bond between residents and urban sounds. Around $92 \%$ of the participants declared that the sounds reminded them of the places that they hear in the city and $80 \%$ of the participants stated that the sounds reminded them of their own memories. Although less attention is paid to sounds within everyday life, there is a strong unconscious emotional bond with sounds, which has the power of bringing back memories.

\section{CONCLUSION}

In order to safeguard sonic ICH in a way that is dynamic rather static, we argued in this paper that the most effective strategy is to design an experiential exhibition that connects the exhibition space with the urban space within which the sonic ICH is found and it offers to increase public awareness of significance and uniqueness of cultural sounds through exhibition and auditory experiences, so that present-day visitors and future generations will make efforts towards safeguarding sonic $\mathrm{ICH}$.

Our research into collecting of cultural sounds leads to a detailed archive of the sonic environment of Istanbul upon which the exhibition is to be based. Although the exhibition plays with various sensory experiences and points to connections between the visuality, aurality and even olfactory aspects of everyday practices, as a result of our preliminary research and observations, we assume that sonic experiences will be the most powerful ones in raising awareness of cultural sounds. This is because both sound itself and experiencing an environment evoke emotions and awaken imagination. The exhibition highlights the most characteristic but disappearing and mostly ignored sounds of the city, such as Turkish bagel vendors, vendors of roasted chestnuts, boza sellers, tea, narghile, kokoreç, backgammon, the nostalgic tramway, markets and bazaars, and horse-drawn carriages by presenting as exhibition experiences. Sonic experiences also remind local visitors of their memories related to Istanbul if they are already familiar with the sounds displayed, and notice that these sounds are part of their past, background, identity or family memories. Foreign visitors may establish connections between the exhibited sonic environment and their own hometowns, and draw comparisons or realize similarities, which also result in reconsidering urban sounds. Thus, experiences make the exhibition message more memorable and impressive, which is, in this case, cultural significance of urban sounds and the need of the protection of cultural sounds. Therefore, designing effective sonic experiences will contribute towards the safeguarding of the sonic cultural heritage of the city by increasing public awareness.

\section{ACKNOWLEDGMENTS}

We would like to thank to Assoc. Prof. Nina Ergin and Assoc. Prof. Asım Evren Yantaç for their valuable contributions and comments, to Koç University for funding The Soundscape of Istanbul project and The Soundsslike Project, and to Hüseyin Kuşcu for his efforts in developing the Soundsslike archive. We also would like to thank profoundly Studio-X Istanbul for organizing the exhibition and the workshops during the exhibition.

\section{REFERENCES}

[1] P. Yelmi, "Protecting contemporary cultural soundscapes as intangible cultural heritage: sounds of Istanbul," International Journal of Heritage Studies, vol. 22 no. 4, pp. 302-311, 2016.

[2] R. Ersoy, 'Performans teori' bağlaminda sözlü kültür ürünleri'nin müzelenmesi sorunu üzerine bazı görüş ve düşünceler,” pp. 57-67. Ankara: Gazi Üniversitesi THBMER, 2004.

[3] S. A. Baghli, "The convention for the safeguarding of the intangible cultural heritage and new perspectives for the museum," ICOM News 4, pp. $15-17,2004$

[4] M. Ekici, "Bir sempozyumun ardindan: Somut olmayan kültürel mirasin müzelenmesi," Milli Folklor, vol. 61, pp. 5-12, 2004.

[5] T. Yin, "Museum and the safeguarding of intangible cultural heritage," The Ethic Arts, 2006. 
[6] A. Altunbas and Ç. Özdemir, Căğdas Müzecilik Anlaylșl ve Ülkemizde Müzeler, Kültür ve Turizm Bakanlığı. Ankara, 2012.

[7] K. Southern, "Exhibitions are our forum for debating change," Museum News vol. 68, no. 8, p. 104, 1989.

[8] R. Russel and K. Winkworth, Significance2.0: A Guide to Assessing the Significance Collections, Collections Council of Australia, 2009.

[9] C. Classen, Worlds of Sense: Exploring the Senses in History and Across Cultures. London: Routledge, 1993.

[10] N. Ergin, "The soundscape of sixteenth-century istanbul mosques: Architecture and qur'an recital," Journal of the Society of Architectural Historians vol. 67, no. 2, pp. 204-210, 2008.

[11] P. Yelmi, H. Kuşcu, and A. E. Yantaç, "Towards a sustainable crowdsourced sound heritage archive by public participation: The soundsslike project," NordiCHI'16, October 23-27, Gothenburg, Sweden, 2016.

[12] N. Shedroff, Experience Design: A Manifesto for Design of Experiences, Experience Design Books, 2009.

[13] R. M. Schafer, Our Sonic Environment and the Tuning of the World The Soundscape, Vermont: Destiny Books Rochester, 1977.

[14] P. Yelmi, "The soundscape of Istanbul: Exploring the public awareness of urban sounds," International Journal of Social Science and Humanity, vol. 7, no. 5, pp. 260-268, 2017.

[15] M. I. Posner, M. J. Nissen, and R. M. Klein, "Visual dominance: An information-processing account of its origins and significance," Psychological Review vol. 83, no. 2, pp.157-171, 1976.

[16] J. Kang, Urban Sound Environment, Taylor\&Francis: New York \& Canada, 2007.

[17] M. Chion, Audio-Vision: Sound on Screen, Colombia University Press: New York, 1990.

[18] G. Rydstrom, "Film sound: How It's done in the real world, course no:12," Sound Synchronization and Sytnthesis for Computer Animation SIGGRAPH '94 VR, Orlando, Florida, 1994.

[19] M. Çorlu, Do we 'see' with our ears too?. [Online]. 03.01.14, 2013. Available: $\quad$ http://www.youtube.com/watch?v=ZN5TvoB-LtA

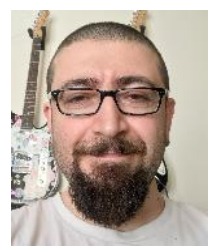

Sertaç Kakı was born in Eskişehir in 1978. He received his bachelor's degree from Istanbul University, Faculty of Science, Astronomy and Space Sciences Department. He completed his master's degree at Istanbul Technical University, Dr. Erol Üçer Center for Advanced Studies in Music (MIAM), Sound Engineering \& Design program and his Ph.D. at Istanbul Technical University, Social Sciences Institute, Musicology and Music Theory Department.
Since 2004, he has been involved over 60 albums, films and documentaries as a recording, mixing and mastering engineer, producer, sound designer, composer and musician. The sound design and installation for 3D environment called 'Soundscape' was exhibited in 2012 at the 1. Istanbul Design Biennial. Another audio and video design/installation called 'Hourly/Spring' was exhibited as a part of 3. Istanbul Design Biennial. He completed his post-doc research in Canada, supported by The Scientific and Technological Research Council of Turkey and ITU, titled as 'Cultural timbre cognition in different cultures and aesthetic bonds', which continued for one year at the University of Calgary. He is currently a faculty member at the ITU Turkish Music State Conservatory, Music Technology Department.

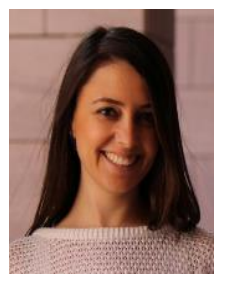

Pınar Yelmi was born in Istanbul in 1985. Yelmi received her bachelor's degree from industrial design at Middle East Technical University (Ankara, Turkey, 2008), her master's degree from Visual Communication Design at Politecnico di Milano (Milano, Italy, 2012), and her PhD degree from Design, Technology and Society program in Koç University (Istanbul, Turkey). Yelmi is currently asisstant professor at Visual Communication Design Department in Işık University.

She worked as industrial designer and graphical designer before her academic career. Her studies on the sounds of Istanbul have started during her Master's education. Having discovered the richness of cultural sounds in Istanbul, she decided to conduct further research under a $\mathrm{PhD}$ program. She conducted "The Soundscape of Istanbul" project (https://soundscapeofistanbul.ku.edu.tr) which is located at the intersection of soundscape studies, intangible cultural heritage, museum studies, sensory studies, interaction design, experience design, exhibition design and participatory design. Her project, being first of its kind in Turkey, is also shared with Europeana Sounds which makes efforts towards protecting Europe's sound heritage. Finally, she initiated a crowdsourced project, "The Soundsslike Project" (http://soundsslike.com), to turn her research project into a global action. She also designs exhibitions to display her projects in various cities.

Yelmi has two awards: One from industrial design area and the other from graphical design. 